Objectives: This is a sub-analysis to evaluate the differences in disease activity and $\mathrm{HS}$ by gender of the patients with AS included in the MIDAS study.

Methods: MIDAS is an observational, non-interventional, cross-sectional, multicenter study. Patients included were $\geq 18$ years old with $\geq 6$ months since diagnosis, were classified by ASAS and modified New York criteria; undergoing treatment $\geq 3$ months. The primary variable was the disease control assessed by the percentage of patients in remission and low disease activity (measured by BASDAI and ASDAS-CRP) ${ }^{1-2}$. Results: We analyzed 313 AS patients; 237 (75.7\%) were male and $76(24.3 \%)$ female (Table 1). Disease control: According to BASDAI <4 (total $64.5 \%$ (mean (SD) $3.1(2.2)) ; 69.2 \%(2.9(2.1))$ of the males vs $50.0 \%(3.8(2.4))$ of the females had a BASDAI <4 (Figure 1A). According to ASDAS-CRP, $57,5 \%$ of the AS patients showed low disease activity (ASDAS-ID + ASDAS-LDA), with a mean (SD) ASDAS-CRP of $1.9(1.1) ; 138(58.2 \%)$ males and 42 (55.3\%) females showed low disease activity (Figure 1B). HS impact was low, with a mean (SD) ASAS-HI of 5.8 (4.4) for AS patients, that was 5.5 (4.4) for males and 6.8 (4.2) for females.

Table 1. Baseline demographic and clinical characteristics of the AS patients analysed.

\begin{tabular}{|c|c|c|c|}
\hline & $\begin{array}{l}\text { Total } \\
(n=313)\end{array}$ & $\begin{array}{l}\text { Male } \\
(n=237)\end{array}$ & $\begin{array}{l}\text { Female } \\
(n=76)\end{array}$ \\
\hline Age (years), mean (SD) & $50.4(12.0)$ & $50.1(12.2)$ & $51.2(11.5)$ \\
\hline Years since diagnosis, mean (SD) & $15.5(11.6)$ & $16.8(12.2)$ & $11.4(8.5)$ \\
\hline $\begin{array}{l}\text { Years since the symptoms' onset to the study } \\
\text { visit, mean (SD) }\end{array}$ & $20.5(12.7)$ & $22.2(13.0)$ & $15.2(9.9)$ \\
\hline $\begin{array}{l}\text { Years since the symptoms' onset to diagnosis, } \\
\text { mean (SD) }\end{array}$ & $5.0(7.2)$ & $5.4(7.7)$ & $3.9(5.6)$ \\
\hline $\mathrm{BMI}\left(\mathrm{kg} / \mathrm{m}^{2}\right)$, mean $(\mathrm{SD})$ & $27.0(4.9)$ & $27.5(4.6)$ & $25.5(5.6)$ \\
\hline $\begin{array}{l}\text { Obesity (BMl>30), n (\%) } \\
\text { Smoking habit }\end{array}$ & $67(23.0 \%)$ & $53(23.7 \%)$ & $14(20.9 \%)$ \\
\hline Current smoker, n (\%) & $75(24.0 \%)$ & $61(25.7 \%)$ & $14(18.4 \%)$ \\
\hline Ex-smoker (>6 months), n (\%) & $81(25.9 \%)$ & $68(28.7 \%)$ & $13(17.1 \%)$ \\
\hline Non-smoker, n (\%) & $137(43.8 \%)$ & $96(40.5 \%)$ & $41(53.9 \%)$ \\
\hline Family history of AS, $n(\%)$ & $66(21.1 \%)$ & $48(20.3 \%)$ & $18(23.7 \%)$ \\
\hline Presence of HLA-B27, n (\%) & $245(78.5 \%)$ & $187(79.2 \%)$ & $58(76.3 \%)$ \\
\hline $\begin{array}{l}\text { Patients previously treated with bDMARD } \\
\text { Active disease, } \mathrm{n}(\%)^{\star}\end{array}$ & $99(31.6 \%)$ & $77(32.5 \%)$ & $22(28.9 \%)$ \\
\hline BASDAI $\geq 4$ & $111(35.5 \%)$ & $73(30.8 \%)$ & $38(50.0 \%)$ \\
\hline ASDAS-CRP $\geq 2.1$ & $133(42.4 \%)$ & $99(41.8 \%)$ & $34(44.7 \%)$ \\
\hline CRP levels (mg/l), mean (SD) & $5.1(8.2)$ & $5.7(9.0)$ & $3.3(4.3)$ \\
\hline PASS, n (\%) & $270(86.3 \%)$ & $208(87.8 \%)$ & $62(81.6 \%)$ \\
\hline ASAS-HI, mean (SD) & $5.8(4.4)$ & $5.5(4.4)$ & $6.8(4.2)$ \\
\hline
\end{tabular}

${ }^{*}$ Refers to the percentage of patients with active disease according to BASDAI $\geq 4$ and ASDASCRP $\geq 2.1$.AS, ankylosing spondylitis; ASAS-HI, Assessment of Spondyloarthritis International Society - Health index; ASDAS, Ankylosing Spondylitis Disease Activity Score; BASDAI, Bath Ankylosing Spondylitis Disease Activity Index; bDMARD: biologic disease modifying anti-rheumatic drug; BMI, body mass index; CRP, C-reactive protein; HLA-B27, human leukocyte antigen B27; PASS, patient acceptable symptom state; SD, standard deviation.

Conclusion: Our analysis showed a higher proportion of females with active disease when using the BASDAl definition. However, when using the ASDAS-CRP definition, these differences by gender seem to be less pronounced. Also, the impact of disease activity on the HS seems to be higher in females than males. As far as we know, this is the first Spanish study to evaluate gender in this patient population. REFERENCES:

[1] Smolen JS et al. Ann Rheum Dis 2018;77:3-17

[2] Gratacós J et al. Reumatol Clin 2018;14:320-33

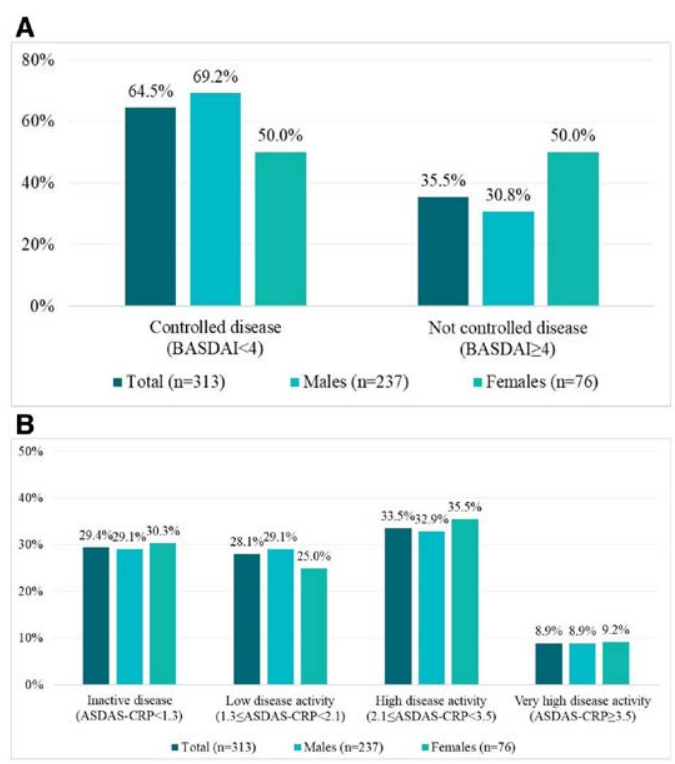

Figure 1. Disease status by sex A)Disease control according to BASDAI B)Disease status according to ASDAS-CRP
ASDAS-CRP, Ankylosing Spondylitis Disease Activity Score- C-reactive protein; BASDAI, Bath Ankylosing Spondylitis Disease Activity Index.

Acknowledgements: We thank to MIDAS group investigators and patients included in the study.

Disclosure of Interests: Cristina Fernández-Carballido Speakers bureau: have received lectures fees from Abbvie, Celgene, Janssen, Lilly, MSD, Novartis, Pfizer, Roche and UCB., Consultant of: I have worked as a paid consultant for Abbvie, Celgene, Janssen, Lilly, Novartis, Pfizer and UCB., Jordi Gratacos-Masmitja Speakers bureau: MSD, Pfizer, AbbVie, Janssen Cilag, Novartis, Lilly and Amgen., Consultant of: MSD, Pfizer, AbbVie, Janssen Cilag, Novartis, Lilly and Amgen., Grant/research support from: During the course of the year I have received a private grand from Pfizer.

I have not received any private influence in the elaboration of the contents of this talk., Eugenio de Miguel Speakers bureau: AbbVie, Novartis, Pfizer, MSD, BMS UCB, Roche, Grunental, Janssen, Sanofi., Paid instructor for: Janssen, Novartis, Roche, Consultant of: AbbVie, Novartis, Pfizer, Galapagos, Grant/research support from: Abbvie, Novartis, Pfizer, Pilar Susana Del Río Martínez Speakers bureau: Novartis, Pfizer, Janssen, Sanofi., Paid instructor for: Lilly, Consultant of: Lilly, Sanofi Aventis, Olga Martínez González Speakers bureau: Novartis, Antonio Fernandez-Nebro Speakers bureau: MSD, Pfizer, AbbVie, Janssen Cilag, Novartis, Celgene, GSK, and Lilly, Consultant of: MSD, Pfizer, AbbVie, Janssen Cilag, Novartis, Celgene, GSK, and Lilly, Paloma Vela-Casasempere Speakers bureau: Astra-Zeneca, AbbVie, Boehringer, GSK, Novartis, UCB, Fresenius-Kabi, Sobi and Lilly, Consultant of: Astra-Zeneca, AbbVie, Boehringer, GSK, Novartis, UCB, Fresenius-Kabi, Sobi and Lilly, Grant/research support from: My unit has received also research support from Roche, MSD, Novartis, Lilly, BMS, and Fresenius-Kabi., Cristina Sanabra Employee of: Novartis employee, Carlos Sastré Employee of: Novartis employee.

DOI: 10.1136/annrheumdis-2021-eular.2420

\section{POS0987 INFLAMMATION OF THE HIP JOINTS IN EARLY AXIAL SPONDYLOATRITIS: DATA ANALYSIS OF VISUALIZATION METHODS}

E. Agafonova ${ }^{1}$, T. Dubinina ${ }^{1}$, A. Demina ${ }^{1}$, D. Rumiantceva ${ }^{1}$, S. Erdes ${ }^{1} .{ }^{1}$ V. A. Nasonova Research Institute of Rheumatology, Laboratory of Spondyloarthritis and Psoriatic Arthritis, Moscow, Russian Federation

Background: According to epidemiological studies in Russia, the inflammation of the hip joints occurs in half of patients with ankylosing spondylitis (AS). There have been practically no studies devoted to the investigations of coxitis in patients with early axial spondyloarthritis $(\operatorname{axSpA})$. It is still unknown what factors cause the development of coxitis in axSpA; there is no generally accepted algorithm for diagnosing this condition, especially at an early stage. Previous studies have shown that coxitis in patients with AS develops on average 5-10 years after the onset of the disease, some patients already have irreversible changes in the hip joint at the time of diagnosis, and some do not develop coxitis never.

Objectives: To compare the clinical manifestations of coxitis with the results of magnetic resonance imaging (MRI), ultrasound (US), and radiography of the hip. Methods: We examined 175 patients (mean age $28.0 \pm 5.92$ years) with axSpA (ASAS, 2009), with a duration of inflammatory back pain of no more than 5 years, from the CoRSaR cohort. The median duration of the disease was 21 [3-60] months. BASDAI - $4.0 \pm 2.0$, BASFI - $2.0[0.4 ; 3.5]$. Among the included patients, 69 (39.4\%) had nr-axSpA, and 106 - AS; 87\% were HLA-B27 positive. All patients underwent US examination of the hip joint. When synovitis was detected, the patients underwent MRI examination of the hip joint. The increase in the cervical-capsular distance (CCD) more than $7 \mathrm{~mm}$ was considered as an ultrasonic coxitis. The median CCD was $7.5[7.0 ; 8.2] \mathrm{mm}$. For coxitis in MRI, osteitis of the head of the hip or acetabulum and synovitis were taken. Radiographic severity of coxitis was determined by BASRI hip.

Results: According to the US data, synovitis of the hip joint was detected in 54 from $175(30.9 \%)$ patients. Pain in the hip joint had $33(61 \%)$ patients. There was no correlation between the intensivity of pain and CCD. CCD significantly correlated with laboratory indicators of disease activity, such as ESR ( $r=0.34$ $p<0.05)$ and CRP $(r=0.3 ; p<0.05)$. Only $7(13.0 \%)$ patients had BASRI hip stages II or III and the rest had normal hip joints. 39 (72\%) had MRI manifestations of coxitis: $36(66 \%)$ patients had synovitis, $1(2 \%)$ had bone marrow edema, and $2(4 \%)$ had a combination of synovitis with osteitis. Patients with and without radiographic coxitis did not differ in terms of disease activity and functional indices.

Conclusion: In early axSPA

- $30.9 \%$ of patients have hip synovitis, and among them, MRI signs of coxitis have $72 \%$, and X-ray coxitis - $13 \%$;

- ultrasound synovitis is only confirmed by MRI in $70 \%$ of cases;

- it seems that the radiological progression of coxitis does not depend on the activity of the disease.

Disclosure of Interests: None declared.

DOI: 10.1136/annrheumdis-2021-eular.2432 